\title{
High concentrations of membrane-fed ivermectin are required for substantial lethal and sublethal impacts on Aedes aegypti
}

\author{
Max Hadlett ${ }^{1 \dagger}$, Sanjay C. Nagi ${ }^{1 *}+\mathbb{D}$, Manas Sarkar ${ }^{2}$, Mark J. I. Paine ${ }^{1}$ and David Weetman ${ }^{1}$
}

\begin{abstract}
Background: With widespread insecticide resistance in mosquito vectors, there is a pressing need to evaluate alternatives with different modes of action. Blood containing the antihelminthic drug ivermectin has been shown to have lethal and sub-lethal effects on mosquitoes. Almost all work to date has been on Anopheles spp., but impacts on other anthropophagic vectors could provide new options for their control, or additional value to anti-malarial ivermectin programmes.

Methods: Using dose-response assays, we evaluated the effects of ivermectin delivered by membrane feeding on daily mortality (up to 14 days post-blood feed) and fecundity of an Indian strain of Aedes aegypti.

Results: The 7-day lethal concentration of ivermectin required to kill $50 \%$ of adult mosquitoes was calculated to be $178.6 \mathrm{ng} / \mathrm{ml}$ (95\% confidence intervals 142.3-218.4) for Ae. aegypti, which is much higher than that recorded for Anopheles spp. in any previous study. In addition, significant effects on fecundity and egg hatch rates were only recorded at high ivermectin concentrations ( $\geq 250 \mathrm{ng} / \mathrm{ul}$ ).

Conclusion: Our results suggest that levels of ivermectin present in human blood at current dosing regimes in mass drug administration campaigns, or even those in a recent higher-dose anti-malaria trial, are unlikely to have a substantial impact on Ae. aegypti. Moreover, owing to the strong anthropophagy of Ae. aegypti, delivery of higher levels of ivermectin in livestock blood is also unlikely to be an effective option for its control. However, other potential toxic impacts of ivermectin metabolites, accumulation in tissues, sublethal effects on behaviour, or antiviral action might increase the efficacy of ivermectin against Ae. aegypti and the arboviral diseases it transmits, and require further investigation.
\end{abstract}

Keywords: Ivermectin, Endectocide, Aedes, Arboviruses, IVM

\footnotetext{
*Correspondence: Sanjay.Nagi@Istmed.ac.uk

${ }^{\dagger}$ Max Hadlett and Sanjay C. Nagi contributed equally to this work

${ }^{1}$ Department of Vector Biology, Liverpool School of Tropical Medicine, Pembroke Place, Liverpool L3 5QA, UK

Full list of author information is available at the end of the article
}

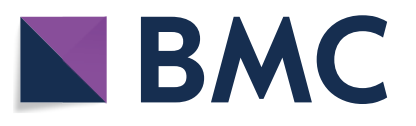

(c) The Author(s) 2021. This article is licensed under a Creative Commons Attribution 4.0 International License, which permits use, sharing, adaptation, distribution and reproduction in any medium or format, as long as you give appropriate credit to the original author(s) and the source, provide a link to the Creative Commons licence, and indicate if changes were made. The images or other third party material in this article are included in the article's Creative Commons licence, unless indicated otherwise in a credit line to the material. If material is not included in the article's Creative Commons licence and your intended use is not permitted by statutory regulation or exceeds the permitted use, you will need to obtain permission directly from the copyright holder. To view a copy of this licence, visit http://creativeco mmons.org/licenses/by/4.0/. The Creative Commons Public Domain Dedication waiver (http://creativecommons.org/publicdomain/ zero/1.0/) applies to the data made available in this article, unless otherwise stated in a credit line to the data. 


\section{Background}

Escalating insecticide resistance [1, 2], recent high profile arboviral outbreaks [3-6] and the stalling of progress towards malaria elimination [7] highlight the need for improved tools to control mosquito vectors. Compounds with alternative modes of action including new and repurposed insecticides for long-lasting insecticidal nets (LLINs) and indoor residual spraying (IRS) are required and are becoming available now, but there remains an urgent need for tools that can target mosquitoes that bite diurnally or bite and rest outdoors $[8$, 9].

Ivermectin is a macrocyclic lactone that displays broad spectrum anti-parasitic activity against both endo- and ecto-parasites, including mosquitoes [1012]. Since the $1990 \mathrm{~s}$, the drug has been extensively used in mass drug administration (MDA) campaigns to eliminate lymphatic filariasis and onchocerciasis in sub-Saharan Africa [13, 14]. During these programmes, reductions in entomological indices and the proportion of Plasmodium-infective mosquitoes have been observed, compatible with mosquitocidal activity of ivermectin $[11,15,16]$. Consequently, ivermectin administration is currently proposed as a novel strategy to reduce malaria transmission [17-19].

Ivermectin primarily targets the glutamate-gated chloride channel; a different mode of action to insecticides currently available on the public health market $[20,21]$, and therefore may be effective against mosquitoes resistant to current insecticides. In addition, a crucial difference from LLINs and IRS is that ivermectin has the potential to protect against mosquitoes displaying alternative biting and resting behaviours [22].

The majority of entomological studies conducted using single ivermectin doses have recorded short-lived mosquitocidal effects ( $<$ days) [10, 15, 16, 23], but delivery methods capable of sustaining higher venous plasma ivermectin concentrations are now being investigated [24, 25]. In a recent randomised controlled trial, prolonged mosquitocidal effects ( $>28$ days) were demonstrated when humans were treated with doses of ivermectin over 3 days; importantly, no significant adverse events were reported when the ivermectin was administered alone or co-administered with a standard anti-malarial treatment [26]. A modelling study based on these data further demonstrated the potential of ivermectin-based MDA for malaria control [27]. In addition, uptake of sub-lethal concentrations of ivermectin has been shown to affect mosquito fecundity, locomotion, ability to re-feed [2832], to inhibit Plasmodium sporogony in the vector [3335] and to adversely affect liver stages of the parasite [36].

In light of the potential for ivermectin MDA to reduce malaria transmission, the majority of research has focused on anopheline vectors. However, in many regions of the tropics, malaria and Aedes-transmitted arboviruses are co-endemic [37]. Given the limited resources available to control arboviral diseases in countries where malaria is a primary target, the effects of systemic ivermectin on other vectors should be examined and the opportunity for cross-disease control in integrated vector management programmes evaluated. Earlier studies have suggested that ivermectin displays significantly lower toxicity to the culicines tested than to anophelines [3841]. However, these studies either did not assess mortality beyond $24 \mathrm{~h}$ after blood-feeding, or did not report at which day the lethal dose [e.g. the lethal concentration required to kill $50 \%\left(\mathrm{LD}_{50}\right)$ of adult mosquitoes] was calculated. In Anopheles gambiae, ivermectin has been shown to affect survival up to 14 days post-blood-feeding [26], and so the potential of delayed mortality in other mosquito vectors also needs evaluation. Additionally, if fecundity is reduced by ivermectin, mosquito populations may be suppressed even if the short-term killing effect is limited. In this study, we conducted laboratory experiments to investigate the effect of imbibed ivermectin on the 14-day survivorship, fecundity, and egg hatch rate of Aedes aegypti.

\section{Methods}

\section{Mosquitoes}

A pyrethroid-susceptible Ae. aegypti strain, founded from an original collection in Mumbai in 2010, and subsequently maintained at the insectaries of Godrej Consumer Products Limited, Mumbai, India, was used. Adults were maintained on $10 \%$ sugar solution at $27 \pm 2{ }^{\circ} \mathrm{C}$ and $80 \pm 10 \%$ relative humidity with a 12 -h light:12-h dark photoperiod. All mosquitoes were bloodfed at 5-7 days post-emergence.

\section{Drugs and reagents}

A powdered ivermectin formulation, dimethyl sulphoxide (DMSO), and phosphate buffered saline (PBS) were obtained from Sigma-Aldrich (St. Louis, MO). Ivermectin was dissolved in DMSO to a concentration of $10 \mathrm{mg} /$ $\mathrm{ml}$ and refrigerated overnight at $4{ }^{\circ} \mathrm{C}$. The $10 \mathrm{mg} / \mathrm{ml}$ ivermectin stock was then serially diluted into PBS to create two working stock solutions: $1 \mathrm{mg} / \mathrm{ml}$ and $0.1 \mathrm{mg} / \mathrm{ml}$. These working stock solutions were diluted further in PBS to achieve final concentrations that were ten times higher than the concentrations required in blood meals (10× stocks). The control stock solution contained PBS with DMSO at a concentration equivalent to the highest concentration of ivermectin working stock. All stocks were stored in sealed conical flasks and refrigerated until required at $4{ }^{\circ} \mathrm{C}$. Final stocks were diluted to $1 \times$ into blood as required. 


\section{Blood-feeding and ivermectin administration}

Defibrinated goat blood sourced from a local abattoir was collected fresh every 2 days and used for all blood feeds. Prior to blood-feeding, mosquitoes were starved of sugar for $6 \mathrm{~h}$. Five- to 7-day-old female mosquitoes were held in $30-\mathrm{cm} \times 30-\mathrm{cm}$ cages and offered blood using a Hemotek feeder (Discovery Workshops, Accrington, UK) (placed on the upper surface) covered with collagen membrane and heated to $37^{\circ} \mathrm{C}$. Mosquitoes were given the opportunity to feed for approximately $30 \mathrm{~min}$. Blood contained ivermectin at the following concentrations: $0 ; 125 ; 175$; 250; 500; 750; 1000; and $1250 \mathrm{ng} / \mathrm{ml}$, which were chosen based on previous studies in culicines.

\section{Mosquito survival}

After experimental blood-feeding, fully engorged females were removed from each cage using a mouth aspirator and placed into empty paper test cups $(n=5$ mosquitoes in each). Mosquitoes were provided with cotton wool soaked in $10 \%$ sugar solution. Mortality was recorded every $24 \mathrm{~h}$ for 14 days post-blood-feeding, with dead mosquitoes removed daily. Owing to logistical constraints, more experimental replicates were performed for the $0,125,250,750$ and $1000 \mathrm{ng} / \mathrm{ml}$ groups than for the 175,500 , and $1250 \mathrm{ng} / \mathrm{ml}$ groups, but a minimum of 60 blood-fed mosquitoes were available per experimental concentration (mean $\pm \mathrm{SD}=97.6 \pm 30.0$ ).

\section{Egg production}

The impact of blood-fed ivermectin on the number of eggs produced from surviving females was assessed using the following methodology: $48 \mathrm{~h}$ post-blood-feeding, surviving mosquitoes were carefully removed from the holding cups using a mouth aspirator and placed individually into fresh oviposition cups. An upturned plastic bottle cap filled with $4 \mathrm{ml}$ of water and a $2-\mathrm{cm} \times 2$-cm square of damp Whatman filter paper was provided as an egglaying substrate. Mosquitoes were provided with cotton wool soaked in $10 \%$ sugar solution on top of the mesh used to seal the cup. Seventy-two hours later (5 days post-blood feed), bottle caps were removed and any eggs were counted using a stereoscopic dissection microscope at $\times 2$ magnification. After counting, all eggs were left on filter paper to dry at ambient room temperature for a further $48 \mathrm{~h}$, prior to determination of hatching rates.

\section{Egg hatch rate}

To analyse whether a sub-lethal dose of ivermectin affected the hatch rate of eggs laid by surviving adults, eggs on filter paper were submerged in $200 \mathrm{ml}$ of filtered water inside $250-\mathrm{ml}$ plastic pots. A sample of 200 eggs randomly selected from the control $(0 \mathrm{ng} / \mathrm{ml})$ and four of the seven treatment groups $(125,175,250$ and $500 \mathrm{ng} / \mathrm{ml})$ were taken for analysis. No eggs were taken from three high concentration treatment groups $(750,1000$ and $1250 \mathrm{ng} / \mathrm{ml}$ ) either because an insufficient number were produced, or because mosquitoes died before oviposition. Ninety-six hours after submersion, larvae from each pot were transferred into new water-filled pots using a mesh net, and the number emerging from each pot was recorded.

\section{Statistical analysis}

The $\mathrm{LC}_{50}$ of adult mosquitoes was calculated using log-probit regression analysis in SPSS version 21 (IBM SPSS). Kaplan-Meier survival analysis followed by a log-rank (Mantel-Cox) test using the survival package in $R$ version 3.6.3 was used to assess the effect of ivermectin on survival of adult females. Egg production data were not normally distributed (Shapiro-Wilk test), therefore a Kruskal-Wallis non-parametric ANOVA was employed to examine variation among concentrations. To assess whether there was any significant difference in the number of eggs produced per surviving female between ivermectin test groups and the negative control group, a post-hoc Dunn's multiple comparison test was used. The effect of ivermectin on egg hatch rate was assessed by comparing the hatch rate between the negative control group and each individual ivermectin group using Fisher's exact tests. Egg production and egg hatch rate data were analysed using GraphPad Prism 7.03.

\section{Results}

A total of 781 Ae. aegypti took blood meals and were used to assess the oral toxicity of blood-fed ivermectin. Kaplan-Meier 14-day survival curves were produced for the daily survival of mosquitoes following the ingestion of ivermectin at concentrations ranging from 0 to $1250 \mathrm{ng} /$ $\mathrm{ml}$ (Fig. 1). Survival was high in the zero-ivermectin control throughout, but ivermectin ingestion significantly reduced the survival of Ae. aegypti mosquitoes (log-rank test, $d f=7, P<2 \mathrm{e}-16)$. This was true for all ivermectin concentrations tested, when compared individually against the control arm and adjusting $p$-values with a Bonferroni correction for multiple testing (log-rank test, $d f=1$, all $P \leq 1 \mathrm{e}-09$ ). Survival was quite high at all concentrations relative to the control group, until the second day after blood-feeding when substantial mortality occurred in a concentration-dependent manner, and by day 4 all females had died at the highest concentration (Fig. 1).

Figure 2 shows dose-response curves at days 3, 7 and 14, and Table 1 shows the resulting estimates for $\mathrm{LC}_{20}$, $\mathrm{LC}_{50}$ and $\mathrm{LC}_{90}$. The $\mathrm{LC}_{50}$ of female Ae. aegypti was dependent on the time after ingestion, with a $35 \%$ lower 
$\mathrm{LC}_{50}$ on day 7 than on day 3 , and a $71 \%$ lower estimate on day 14, demonstrating the delayed mortality effect of ivermectin.

Ivermectin-feeding exerted a significant impact on the fecundity of surviving female Ae. aegypti (Fig. 3a). Whilst fecundity at $125 \mathrm{ng} / \mathrm{ml}$ was similar to that of the unexposed control group, each higher concentration significantly reduced the mean number of eggs produced, with fecundity following the highest dose reduced 20 times compared to the control group (Table 2). In addition to its effect on fecundity, ivermectin also reduced the egg hatch rate of surviving Ae. aegypti females (Fig. 3b). Similar to effects on fecundity, exposure to $125 \mathrm{ng} / \mathrm{ml}$ had little impact on hatch rate, but this was significantly reduced at the higher concentrations (for which sufficient egg numbers were available), with an approximately fourfold reduction at $500 \mathrm{ng} / \mathrm{ml}$ (Table 2).

\section{Discussion}

Ivermectin holds significant promise to expand the current vector control toolbox. Alongside its excellent human safety profile and lack of impact on non-haematophagous insects, it has the potential to impact disease transmission occurring outdoors, and a novel mode of action which may circumvent insecticide resistance. Though it has proven effective at killing Anopheles mosquitoes, little research to date has focused on its effect on other disease vectors. In this study we assessed the effect of ivermectin on survivorship, fecundity and egg hatch rate in Ae. aegypti.

Survival of Ae. aegypti declined significantly when it membrane-fed on blood containing ivermectin, at all concentrations tested. In concordance with previous studies, the lethal dose for ivermectin was relatively high, with a 7-day $\mathrm{LC}_{50}$ of $178.6 \mathrm{ng} / \mathrm{ml}$. This is in agreement with a previous study which estimated 7-day $\mathrm{LC}_{50} \mathrm{~s}$ for multiple Ae. aegypti strains ranging from 187.17 to $576.43 \mathrm{ng} / \mathrm{ml}$ [39]. For comparison, recent studies have demonstrated 7-day $\mathrm{LC}_{50}$ doses for Anopheles spp. ranging between 3.35 and $55.6 \mathrm{ng} / \mathrm{ml}$ [23, 34, 42-44].

In MDA campaigns to control filarial disease, ivermectin is typically delivered as a single dose at approximately $150-200 \mu \mathrm{g} / \mathrm{kg}$ [45]. These single doses have been shown to cause mosquitocidal effects for only short periods of less than 7 days $[10,15,16,44]$. Ivermectin has a half-life of approximately $18 \mathrm{~h}$, and at doses of $150-200 \mu \mathrm{g} / \mathrm{kg}$ typical peak venous plasma concentrations are in the range of $10-70 \mathrm{ng} / \mathrm{ml}$ [46]. A recent randomised controlled trial in Kenya demonstrated prolonged mosquitocidal effects of ivermectin for up to 28 days after administration against An. gambiae, through 3-day dosing of 300 and $600 \mu \mathrm{g} / \mathrm{kg}$ [26]. In pharmacokinetic data from the same trial, a median maximum recorded concentration $\left(C_{\max }\right)$ of ivermectin of $105.2 \mathrm{ng} / \mathrm{ml}$ was found in venous blood at the highest dose, with the time to reach $C_{\max }$ of approximately $4 \mathrm{~h}$ [47]. That peak ivermectin concentration surpasses the 7-day $\mathrm{LC}_{20}$ for the Ae. aegypti strain used in the present study. However, a potential caveat is that there could be an additional impact from metabolites of ivermectin, which are present in human blood days after administration, and which are toxic to mosquitoes. This was suggested by the observation that the

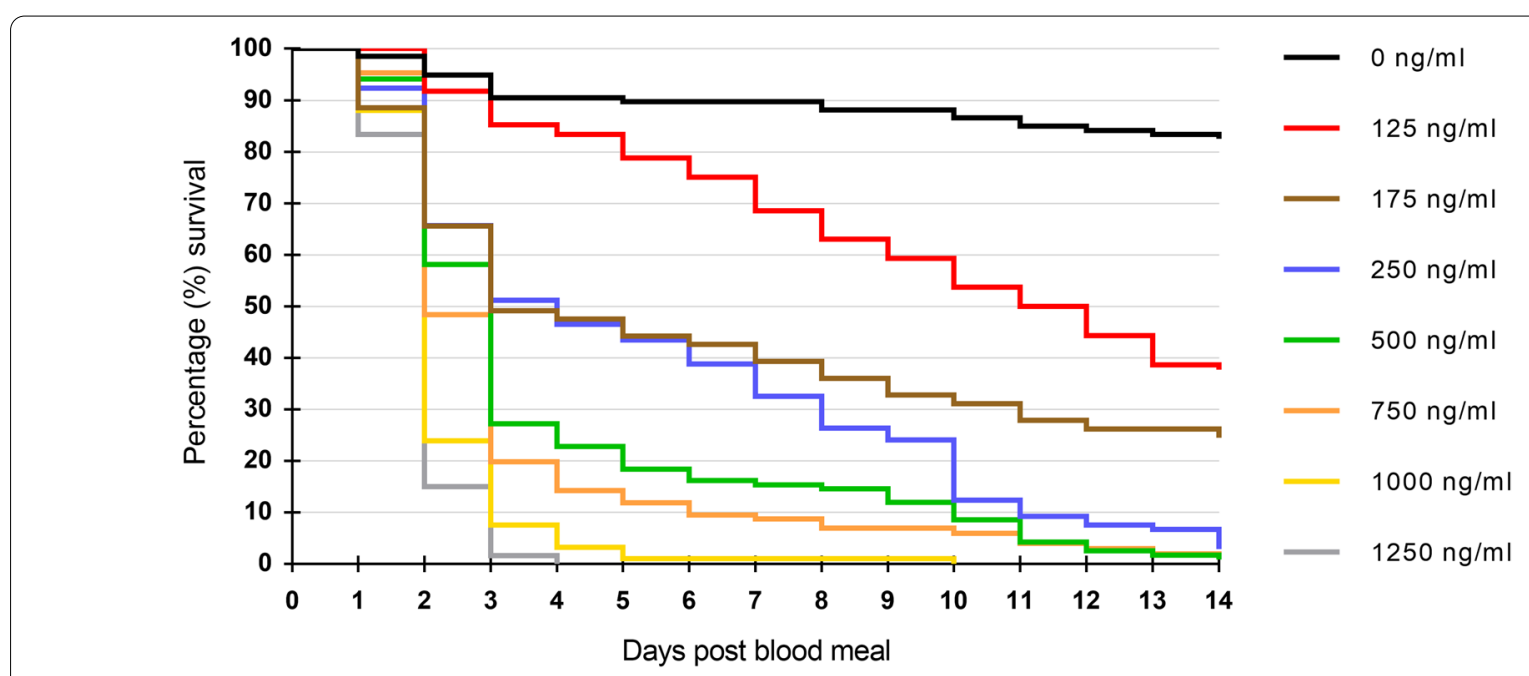

Fig. 1 Fourteen-day Kaplan-Meier survival curves showing the daily survival of Aedes aegypti following ingestion of ivermectin at varying concentrations 

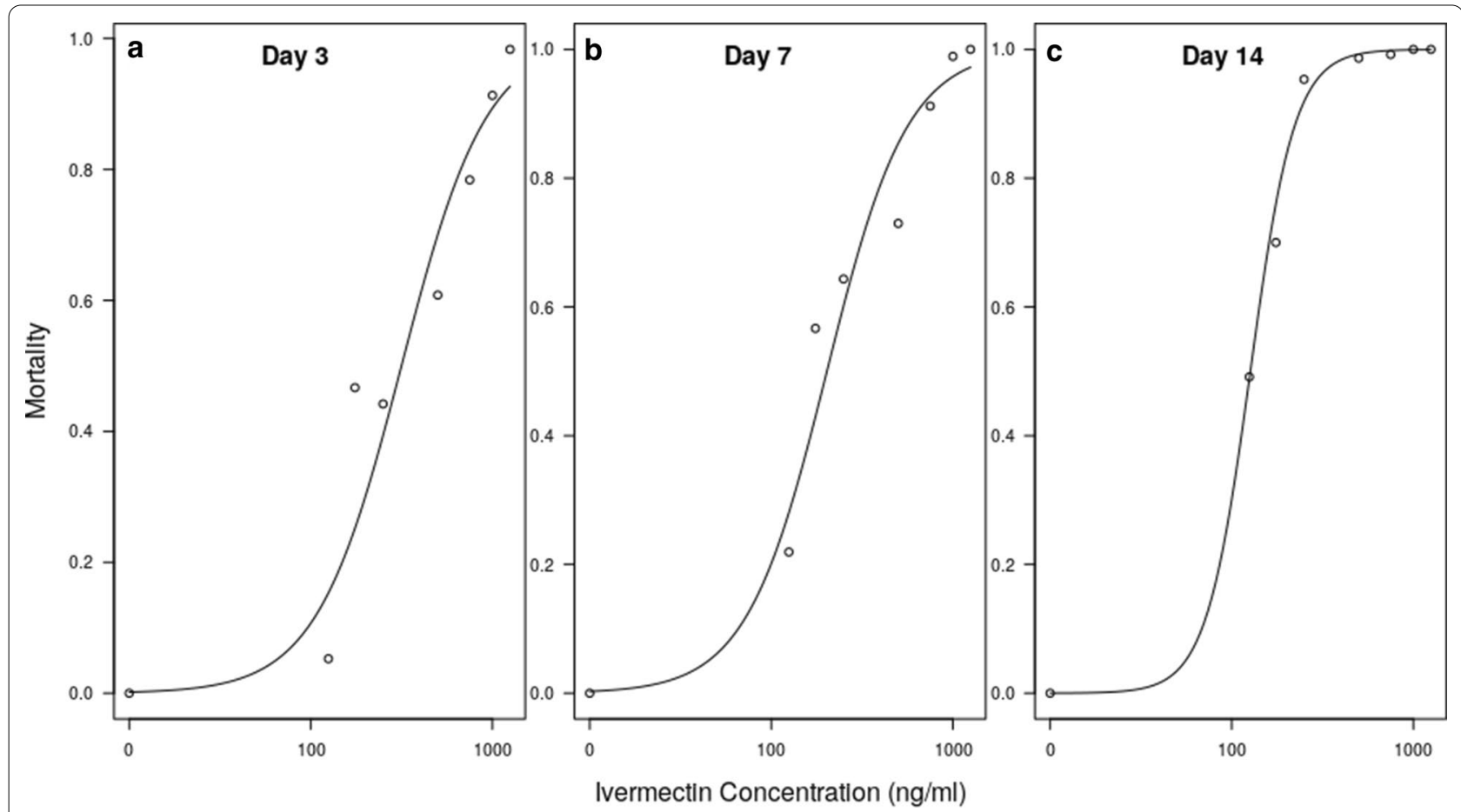

Fig. 2 Dose-response curves of membrane-fed ivermectin against Ae. aegypti at a day 3, b day 7, c day 14

Table 1 Lethal concentrations $(L C)$ of ivermectin for Aedes aegypti at days 3, 7 and 14 post-blood-feeding, calculated using probit analysis

\begin{tabular}{llll}
\hline \multirow{2}{*}{ LC (\%) } & \multicolumn{3}{l}{ Ivermectin concentration (ng/ml) (95\% confidence interval) } \\
\cline { 2 - 4 } & Day 3 & Day 7 & Day 14 \\
\hline 20 & $125.5(94.1-157.5)$ & $81.6(58.6-105.6)$ & $36.3(23.2-51.3)$ \\
50 & $274.7(225.6-330.1)$ & $178.6(142.3-218.4)$ & $79.5(57.1-104.9)$ \\
90 & $905.4(723.5-1202.3)$ & $588.8(473.9-765.9)$ & $262.1(203.2-344.2)$ \\
\hline
\end{tabular}

duration of mortality observed in An. gambiae was far longer than that projected by pharmacokinetic models $[26,45]$; however, subsequent analysis showed it was not necessary to invoke this mechanism [47]. Whilst it seems clear that the duration of efficacy is likely to be much shorter in Ae. aegypti relative to Anopheles spp. for any given dose, the precise impact of ivermectin in human venous blood on Ae aegypti requires further investigation.

Another important factor is the capacity of ivermectin to exhibit a range of sub-lethal effects in mosquitoes, meaning that it could still impact disease transmission through reductions in mosquito fecundity, egg hatching, or ability to re-feed. We found a significant impact of ivermectin in reducing fecundity, and also egg hatch rates, at concentrations $\geq 250 \mathrm{ng} / \mathrm{ml}$ (Fig. 3). At the lowest concentration tested $(125 \mathrm{ng} / \mathrm{ml})$, there was no difference in the mean number of eggs laid, nor in the egg hatch rate. This concentration is higher than that found in human blood even at a high dosing regime [48], and thus it seems unlikely that ivermectin would have a measurable impact on $A e$. aegypti via sub-lethal impacts. However, it is important to note both the caveat above (potentially toxic metabolites), and also that, in Ae. aegypti, effects on fitnessrelated behaviours such as the ability to re-feed have yet to be explored.

Ivermectin has also been proposed as a veterinary endectocide [31, 49,50]. Deployed in this manner, much higher ivermectin concentrations could potentially be reached; however, Ae. aegypti typically displays limited zoophagic behaviour and effects are likely to be limited accordingly. However, an impact remains possible for other important arbovirus vectors that display more plasticity in feeding behaviour, such as Aedes albopictus [51-54].

A limitation of the study was that the membrane feeds were conducted solely on a single relatively homogeneous laboratory strain of Ae. aegypti, which may now differ substantially from the field mosquitoes 


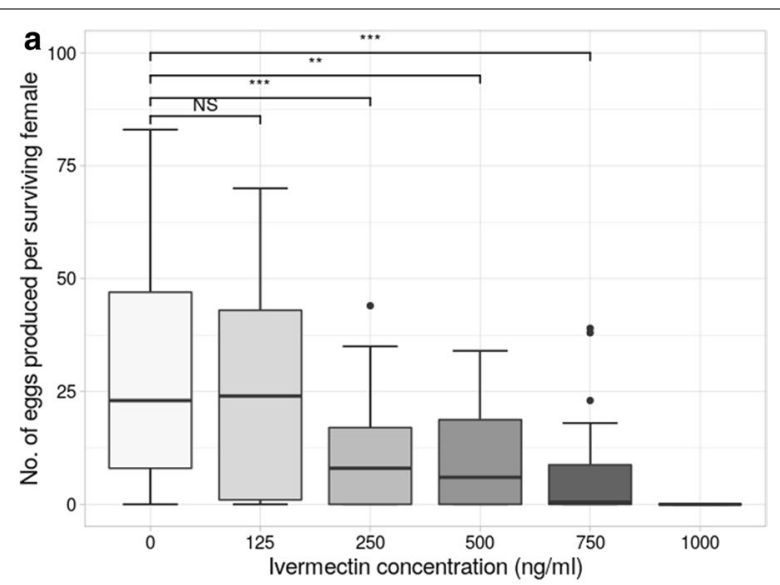

b

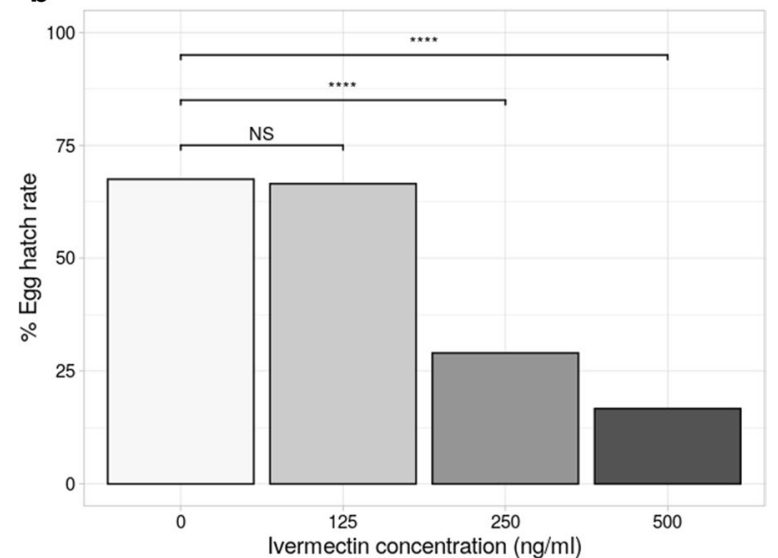

Fig. 3 a, b Reproductive output of Ae. aegypti following ivermectin ingestion. a Average number of eggs produced per surviving female mosquito. $\mathbf{b}$ Hatch rate (\%) of eggs produced by surviving females. Asterisks represent the level of statistical difference from the control group $(0 \mathrm{ng} / \mathrm{ml}) ;{ }^{*} P<0.05,{ }^{* *} P<0.01$, ${ }^{* *} P<0.001$, ${ }^{* * *} P<0.0001$; groups that did not differ significantly from each other are grouped by a horizontal line above the bars

from which it was originally established. Additionally, ivermectin is currently proposed as a control tool primarily in sub-Saharan Africa; compared to Asian populations, African Ae aegypti are known to differ genetically and exhibit phenotypic differences, such as in susceptibility to arboviral infections, or mechanisms of resistance to insecticides $[37,55,56]$. Another possible limitation is that ivermectin was delivered systemically via Hemotek membrane feeding, and this method of delivery may inaccurately represent ivermectin uptake compared to direct blood-feeding on humans. For example, it has been suggested that ivermectin, as a lipophilic compound, may accumulate in dermal and adipose tissue and therefore reach higher concentrations than that found in venous plasma [57]. As mosquitoes imbibe blood from subdermal capillaries, they may ingest concentrations of ivermectin higher than those found in venous plasma [57]. Despite this concern, a recent study, nested within a randomised controlled trial, found similar mosquitocidal effects of ivermectin when comparing membrane feeding to direct skin feeding [43].

Finally, it remains possible that arbovirus replication and transmission could be directly inhibited by ivermectin. For example, a recent study demonstrated the antiviral activity of ivermectin against dengue serotype 2 when blood-fed to Ae. albopictus [58]. Additionally, in vitro enzymatic assays have shown ivermectin to inhibit the replication of other flaviviruses, such as yellow fever virus [59]. Whether sub-lethal concentrations of ivermectin could affect vector competence for arboviruses in the mosquito host should be explored further.

In conclusion, we have demonstrated through membrane feeding experiments that high concentrations of ivermectin are required to induce mortality and affect the fecundity of Ae. aegypti. Therefore, potential control strategies employing ivermectin MDA are unlikely to have a substantial impact on Aedes-transmitted arboviral disease. However, further research is necessary to determine if ivermectin exhibits additional effects such as sublethality and antiviral activity.

Table 2 Fecundity of Ae. aegypti following ingestion of ivermectin at varying concentrations

\begin{tabular}{|c|c|c|c|c|}
\hline Ivermectin (ng/ml) & No. of mosquitoes fed & $\begin{array}{l}\text { No. of surviving females on day } 3 \\
\text { (\% survival) }\end{array}$ & $\begin{array}{l}\text { Mean no. of eggs laid/surviving } \\
\text { female } \pm \text { SEM }\end{array}$ & $\begin{array}{l}\% \text { Hatch rate (no. of } \\
\text { hatched larvae/no. of eggs } \\
\text { submerged) }\end{array}$ \\
\hline 0 & 67 & 60 (89.6) & $28.4 \pm 2.9$ & $69(138 / 200)$ \\
\hline 125 & 54 & $49(90.7)$ & $23.5 \pm 2.9$ & $66.5(133 / 200)$ \\
\hline 250 & 69 & $44(63.7)$ & $10.8 \pm 1.7$ & $29(58 / 200)$ \\
\hline 500 & 74 & $26(35.1)$ & $10.0 \pm 2.3$ & $16.7(25 / 150)$ \\
\hline 750 & 65 & $18(27.7)$ & $7.8 \pm 3.1$ & $-^{a}$ \\
\hline 1000 & 32 & $3(9.4)$ & $0 \pm 0$ & $-^{\mathrm{a}}$ \\
\hline
\end{tabular}

SEM standard error of the mean

a Hatch rate was not calculated for eggs of mosquitoes exposed to $\geq 750 \mathrm{ng} / \mathrm{ml}$ 


\section{Acknowledgements}

We would like to express our thanks to the staff at Research and Development, Godrej PLC for their assistance in rearing the mosquitoes for the bioassays, and to Rhiannon Logan for preparing the equipment. We would like to thank two anonymous reviewers for their comments on the manuscript.

\section{Authors' contributions}

DW, MP and MS conceived and designed the experiments. MH and SCN performed the experiments and analyses. SCN, DW and $\mathrm{MH}$ wrote the manuscript. All the authors read and approved the final manuscript.

\section{Funding}

Funding for materials and supplies was provided by Godrej PLC and through Liverpool School of Tropical Medicine MSc dissertation project channels.

\section{Availability of data}

Data are available from the corresponding author on request.

\section{Ethics approval and consent to participate}

Not applicable.

\section{Consent for publication}

Not applicable.

\section{Competing interests}

The authors declare that they have no competing interests.

\section{Author details}

${ }^{1}$ Department of Vector Biology, Liverpool School of Tropical Medicine, Pembroke Place, Liverpool L3 5QA, UK. ${ }^{2}$ Research and Development, Global Innovation-Pest Category, Reckitt Benckiser, Sector 32, Gurgaon, Haryana 122001, India.

Received: 22 September 2020 Accepted: 1 December 2020

Published online: 06 January 2021

\section{References}

1. Hemingway J, Ranson H, Magill A, Kolaczinski J, Fornadel C, Gimnig J, et al. Averting a malaria disaster: will insecticide resistance derail malaria control? Lancet. 2016:387:1785-8.

2. Ranson H, Lissenden N. Insecticide resistance in African Anopheles mosquitoes: a worsening situation that needs urgent action to maintain malaria control. Trends Parasitol. 2016;32:187-96.

3. Bhatt S, Gething PW, Brady OJ, Messina JP, Farlow AW, Moyes CL, et al. The global distribution and burden of dengue. Nature. 2013;496:504-7.

4. Weaver SC, Charlier C, Vasilakis N, Lecuit M. Zika, Chikungunya, and other emerging vector-borne viral diseases. Annu Rev Med. 2017;69:395-408.

5. Fauci AS, Morens DM. Zika virus in the Americas-yet another arbovirus threat. N Engl J Med. 2016;374:602-4.

6. Wilder-Smith A, Gubler DJ, Weaver SC, Monath TP, Heymann DL, Scott TW. Epidemic arboviral diseases: priorities for research and public health. Lancet Infect Dis. 2017;17:e101-6.

7. World Health Organization. World malaria report 2018. Geneva: World Health Organization; 2018.

8. Makungu C, Stephen S, Kumburu S, Govella NJ, Dongus S, Hildon ZJL, et al. Informing new or improved vector control tools for reducing the malaria burden in Tanzania: a qualitative exploration of perceptions of mosquitoes and methods for their control among the residents of Dar es Salaam. Malar J. 2017:16:410.

9. Killeen GF, Marshall JM, Kiware SS, South AB, Tusting LS, Chaki PP, et al. Measuring, manipulating and exploiting behaviours of adult mosquitoes to optimise malaria vector control impact. BMJ Glob Health. 2017;2:e000212.

10. Chaccour C, Lines J, Whitty CJM. Effect of ivermectin on Anopheles gambiae mosquitoes fed on humans: the potential of oral insecticides in malaria control. J Infect Dis. 2010;202:113-6.

11. Bockarie MJ, Hii JLK, Alexander NDE, Bockarie F, Dagoro H, Kazura JW, et al. Mass treatment with ivermectin for filariasis control in Papua New Guinea: Impact on mosquito survival. Med Vet Entomol. 1999;13:120-3.
12. Wilson ML. Avermectins in arthropod vector management-prospects and pitfalls. Parasitol Today. 1993;9:83-7.

13. Ichimori K, King JD, Engels D, Yajima A, Mikhailov A, Lammie P, et al. Global programme to eliminate lymphatic filariasis: the processes underlying programme success. PLoS Negl Trop Dis. 2014;8:e3328.

14. Taylor MJ, Hoerauf A, Bockarie M. Lymphatic filariasis and onchocerciasis. Lancet. 2010:376:1175-85.

15. Kobylinski KC, Sylla M, Chapman PL, Sarr MD, Foy BD. Ivermectin mass drug administration to humans disrupts malaria parasite transmission in Senegalese villages. Am J Trop Med Hyg. 2011;85:3-5.

16. Sylla M, Kobylinski KC, Gray M, Chapman PL, Sarr MD, Rasgon JL, et al. Mass drug administration of ivermectin in south-eastern Senegal reduces the survivorship of wild-caught, blood fed malaria vectors. Malar J. 2010;9:365

17. Foy BD, Kobylinski KC, da Silva IM, Rasgon JL, Sylla M. Endectocides for malaria control. Trends Parasitol. 2011;27:423-8.

18. Chaccour CJ, Kobylinski KC, Bassat Q, Bousema T, Drakeley C, Alonso P, et al. Ivermectin to reduce malaria transmission: a research agenda for a promising new tool for elimination. Malar J. 2013;12:153.

19. Kobylinski KC, Alout H, Foy BD, Clements A, Adisakwattana P, Swierczewski $\mathrm{BE}$, et al. Rationale for the coadministration of albendazole and ivermectin to humans for malaria parasite transmission control. Am J Trop Med Hyg. 2014;91:655-62.

20. Meyers Jl, Gray M, Kuklinski W, Johnson LB, Snow CD, Black WC, et al. Characterization of the target of ivermectin, the glutamate-gated chloride channel, from Anopheles gambiae. J Exp Biol. 2015;218:1478-86.

21. Cully DF, Paress PS, Liu KK, Schaeffer JM, Arena JP. Identification of a Drosophila melanogaster glutamate-gated chloride channel sensitive to the antiparasitic agent avermectin. J Biol Chem. 1996;271:20187-91.

22. Alout H, Krajacich B, Meyers J, Grubaugh N, Brackney D, Kobylinski K, et al. Evaluation of ivermectin mass drug dministration for malaria transmission control across different West African environments. Malar J. 2014;13:417.

23. Ouédraogo AL, Bastiaens GJH, Tiono AB, Guelbéogo WM, Kobylinski KC, Ouédraogo $A$, et al. Efficacy and safety of the mosquitocidal drug ivermectin to prevent malaria transmission after treatment: a double-blind, randomized, clinical trial. Clin Infect Dis. 2015;60:357-65.

24. Chaccour CJ, Rabinovich NR. Oral, slow-release ivermectin: biting back at malaria vectors. Trends Parasitol. 2017:33:156-8.

25. Chaccour C, Barrio A, Royo A, Urbistondo D, Slater H, Hammann F, et al. Screening for an ivermectin slow-release formulation suitable for malaria vector control. Malar J. 2015;14:102.

26. Smit MR, Ochomo EO, Aljayyoussi G, Kwambai TK, Abongo BO, Chen T, et al. Safety and mosquitocidal efficacy of high-dose ivermectin when co-administered with dihydroartemisinin-piperaquine in Kenyan adults with uncomplicated malaria (IVERMAL): a randomised, double-blind, placebo-controlled trial. Lancet Infect Dis. 2018;3099:1-12.

27. Slater HC, Foy BD, Kobylinski K, Chaccour C, Watson OJ, Hellewell J, et al. Ivermectin as a novel complementary malaria control tool to reduce incidence and prevalence: a modelling study. Lancet Infect Dis. 2020;20:498-508

28. Lyimo IN, Kessy ST, Mbina KF, Daraja AA, Mnyone LL. Ivermectin-treated cattle reduces blood digestion, egg production and survival of a freeliving population of Anopheles arabiensis under semi-field condition in south-eastern Tanzania. Malar J. 2017;16:1-12.

29. Sampaio VS, Beltrán TP, Kobylinski KC, Melo GC, Lima JBP, Silva SGM, et al. Filling gaps on ivermectin knowledge: effects on the survival and reproduction of Anopheles aquasalis, a Latin American malaria vector. Malar J. 2016;15:1-9.

30. Fritz ML, Walker ED, Miller JR. Lethal and sublethal effects of avermectin/ milbemycin parasiticides on the African malaria vector Anopheles arabiensis. J Med Entomol. 2012;49:326-31.

31. Pooda HS, Rayaisse JB, Hien DFDS, Lefèvre T, Yerbanga SR, Bengaly Z, et al. Administration of ivermectin to peridomestic cattle: a promising approach to target the residual transmission of human malaria. Malar J. 2015;14:1-2.

32. Fritz ML, Siegert PY, Walker ED, Bayoh MN, Vulule JR, Miller JR. Toxicity of bloodmeals from ivermectin-treated cattle to Anopheles gambiae s.l. Ann Trop Med Parasitol. 2009:103:539-47.

33. Kobylinski KC, Foy BD, Richardson JH. Ivermectin inhibits the sporogony of Plasmodium falciparum in Anopheles gambiae. Malar J. 2012;11:381. 
34. Kobylinski KC, Escobedo-Vargas KS, López-Sifuentes VM, Durand S, Smith ES, Baldeviano GC, et al. Ivermectin susceptibility, sporontocidal effect, and inhibition of time to re-feed in the Amazonian malaria vector Anopheles darlingi. Malar J. 2017;16:1-9.

35. Pinilla YT, Lopes SCP, Sampaio VS, Andrade FS, Melo GC, Orfano AS, et al. Promising approach to reducing Malaria transmission by ivermectin: sporontocidal effect against Plasmodium vivax in the South American vectors Anopheles aquasalis and Anopheles darlingi. PLoS Negl Trop Dis. 2018;1-23.

36. Mendes AM, Albuquerque IS, Machado M, Pissarra J, Meireles P, Prudincio M. Inhibition of Plasmodium liver infection by ivermectin. Antimicrob Agents Chemother. 2017;61:1-8

37. Moyes C, Vontas J, Martins A, Ng L, Koou S, Dusfour l, et al. Contemporary status of insecticide resistance in the major Aedes vectors of arboviruses infecting humans. PLoS Negl Trop Dis. 2017;7:1-20.

38. Derua YA, Kisinza WN, Simonsen PE. Differential effect of human ivermectin treatment on blood feeding Anopheles gambiae and Culex quinquefasciatus. Parasites Vectors. 2015:8:130.

39. Deus KM, Saavedra-Rodriguez K, Butters MP, Black WC, Foy BD. The effect of ivermectin in seven strains of Aedes aegypti (Diptera: Culicidae) including a genetically diverse laboratory strain and three permethrin resistant strains. J Med Entomol. 2012;49:356-63.

40. Whitehorn J, Thi LV, Dui LT, Simmons CP. Aedes aegypti (L.) survival after exposure to ivermectin. Southeast Asian J Trop Med Public Health. 2013:44:179.

41. Gardner K, Meisch MV, Meek CL, Biven WS. Effects of ivermectin in canine blood on Anopheles quadrimaculatus, Aedes albopictus and Culex salinarius. J Am Mosq Control Assoc. 1993;9:400-2.

42. Kobylinski KC, Ubalee R, Ponlawat A, Nitatsukprasert C, Phasomkulsolsil S, Wattanakul T, et al. Ivermectin susceptibility and sporontocidal effect in Greater Mekong Subregion Anopheles. Malar J. 2017;16:1-13.

43. Smit MR, Ochomo EO, Aljayyoussi G, Kwambai TK, Abongo BO, Bousema $T$, et al. Human direct skin feeding versus membrane feeding to assess the mosquitocidal efficacy of high-dose ivermectin (IVERMAL trial). Clin Infect Dis. 2019;69:1112-9.

44. Kobylinski KC, Deus KM, Butters MT, Hongyu T, Gray M, Silva M, et al. The effect of oral anthelmintics on the survivorship and re-feeding frequency of anthropophilic mosquito disease vectors marques. Acta Trop. 2011;116:119-26.

45. González Canga A, Sahagún Prieto AM, Diez Liébana MJ, Fernández Martínez N, Sierra Vega M, García Vieitez JJ. The pharmacokinetics and interactions of ivermectin in humans - a mini-review. AAPS J. 2008:10:42-6.

46. Merck. Stromectol (ivermectin). FDA approved package insert; 2009. 2014. p. 1-7.

47. Smit MR, Ochomo EO, Waterhouse D, Kwambai TK, Abong'o BO, Bousema T, et al. Pharmacokinetics-pharmacodynamics of high-dose ivermectin with dihydroartemisinin-piperaquine on mosquitocidal activity and QT-prolongation (IVERMAL). Clin Pharmacol Ther. 2018;105:388-401.

48. Smit MR, Ochomo EO, Waterhouse D, Kwambai TK, Abongo BO, Bousema $T$, et al. Pharmacokinetics-pharmacodynamics of high-dose ivermectin with dihydroartemisinin-piperaquine on mosquitocidal activity and QTprolongation (IVERMAL). Clin Pharmacol Ther. 2019;105:388-401.

49. Chaccour C, Killeen GF. Mind the gap: residual malaria transmission, veterinary endectocides and livestock as targets for malaria vector control. Malar J. 2016:15:24.

50. Poché RM, Burruss D, Polyakova L, Poché DM, Garlapati RB. Treatment of livestock with systemic insecticides for control of Anopheles arabiensis in western Kenya. Malar J. 2015;14:351.

51. Sivan A, Shriram AN, Sunish IP, Vidhya PT. Host-feeding pattern of Aedes aegypti and Aedes albopictus (Diptera: Culicidae) in heterogeneous landscapes of South Andaman, Andaman and Nicobar Islands India. Parasitol Res. 2015;114:3539-46.

52. Richards SL, Ponnusamy L, Unnasch TR, Hassan HK, Apperson CS. Hostfeeding patterns of Aedes albopictus (Diptera: Culicidae) in relation to availability of human and domestic animals in suburban landscapes of Central North Carolina. J Med Entomol. 2008;43:543-51.

53. Tempelis $\mathrm{CH}$, Hayes RO, Hess AD, Reeves WC. Blood-feeding habits of four species of mosquito found in Hawaii. Am J Trop Med Hyg. 1970;19:335-41.

54. Delatte H, Desvars A, Bouétard A, Bord S, Gimonneau G, Vourch G, et al. Blood-feeding behavior of Aedes albopictus, a vector of Chikungunya on La Reunion. Vector-Borne Zoonotic Dis. 2010;10:249-58.

55. Aubry F, Martynow D, Baidaliuk A, Merkling SH, Dickson LB, Claudia M, et al. Worldwide survey reveals lower susceptibility of African Aedes aegypti mosquitoes to diverse strains of Zika virus. bioRxiv. 2018;1-8.

56. Weetman D, Kamgang B, Badolo A, Moyes C, Shearer F, Coulibaly M, et al. Aedes mosquitoes and Aedes-borne arboviruses in Africa: current and future threats. Int J Environ Res Public Health. 2018;15:220.

57. Chaccour C, Hammann F, Rabinovich NR. Ivermectin to reduce malaria transmission. I. Pharmacokinetic and pharmacodynamic considerations regarding efficacy and safety. Malar J. 2017;16:1-16.

58. Xu T, Han Y, Liu W, Pang X, Zheng B, Zhang Y, et al. Antivirus effectiveness of ivermectin on dengue virus type 2 in Aedes albopictus. PLoS Negl Trop Dis. 2018;12:1-14.

59. Mastrangelo E, Pezzullo M, De Burghgraeve T, Kaptein S, Pastorino B, Dallmeier $\mathrm{K}$, et al. Ivermectin is a potent inhibitor of flavivirus replication specifically targeting NS3 helicase activity: new prospects for an old drug. J Antimicrob Chemother. 2012;67:1884-94.

\section{Publisher's Note}

Springer Nature remains neutral with regard to jurisdictional claims in published maps and institutional affiliations.
Ready to submit your research? Choose BMC and benefit from:

- fast, convenient online submission

- thorough peer review by experienced researchers in your field

- rapid publication on acceptance

- support for research data, including large and complex data types

- gold Open Access which fosters wider collaboration and increased citations

- maximum visibility for your research: over $100 \mathrm{M}$ website views per year

At $\mathrm{BMC}$, research is always in progress.

Learn more biomedcentral.com/submissions 